\title{
Damage by wind-blown sand and its control measures along the Taklimakan Desert Highway in China
}

\author{
LI Congjuan $^{1,2}$, WANG Yongdong ${ }^{1,2^{*}}$, LEI Jiaqiang ${ }^{1,2^{*}}$, XU Xinwen $^{1,2}$, WANG Shijie ${ }^{1,2,3}$, \\ FAN Jinglong ${ }^{1,2}$, LI Shengyu ${ }^{1,2}$ \\ ${ }^{1}$ National Engineering Technology Research Center for Desert-Oasis Ecological Construction, Xinjiang Institute of Ecology \\ and Geography, Chinese Academy of Sciences, Urumqi 830011, China; \\ ${ }^{2}$ Taklimakan Desert Research Station, Xinjiang Institute of Ecology and Geography, Chinese Academy of Sciences, Korla \\ 841000, China; \\ ${ }^{3}$ Xinjiang Agricultural University, Urumqi 830052, China
}

\begin{abstract}
Desertification is one of the most serious environmental problems in the world, especially in the arid desert regions. Combating desertification, therefore, is an urgent task on a regional or even global scale. The Taklimakan Desert in China is the second largest mobile desert in the world and has been called the "Dead Sea" due to few organisms can exist in such a harsh environment. The Taklimakan Desert Highway, the longest desert highway (a total length of $446 \mathrm{~km}$ ) across the mobile desert in the world, was built in the 1990s within the Taklimakan Desert. It has an important strategic significance regarding oil and gas resources exploration and plays a vital role in the socio-economic development of southern Xinjiang, China. However, wind-blow sand seriously damages the smoothness of the desert highway and, in this case, mechanical sand control system (including sand barrier fences and straw checkerboards) was used early in the life of the desert highway to protect the road. Unfortunately, more than $70 \%$ of the sand barrier fences and straw checkerboards have lost their functions, and the desert highway has often been buried and frequently blocked since 1999. To solve this problem, a long artificial shelterbelt with the length of $437 \mathrm{~km}$ was built along the desert highway since 2000. However, some potential problems still exist for the sustainable development of the desert highway, such as water shortage, strong sandstorms, extreme environmental characteristics and large maintenance costs. The study aims to provide an overview of the damages caused by wind-blown sand and the effects of sand control measures along the Taklimakan Desert Highway. Ultimately, we provide some suggestions for the biological sand control system to ensure the sustainable development of the Taklimakan Desert Highway, such as screening drought-resistant species to reduce the irrigation requirement and ensure the sound development of groundwater, screening halophytes to restore vegetation in the case of soil salinization, and planting cash crops, such as Cistanche, Wolfberry, Apocynum and other cash crops to decrease the high cost of maintenance on highways and shelterbelts.
\end{abstract}

Keywords: wind-blown sand; sand barrier fences; artificial shelterbelt; mechanical sand control measure; biological sand control measure; sustainable development; Taklimakan Desert Highway

Citation: LI Congjuan, WANG Yongdong, LEI Jiaqiang, XU Xinwen, WANG Shijie, FAN Jinglong, LI Shengyu. 2021. Damage by wind-blown sand and its control measures along the Taklimakan Desert Highway in China. Journal of Arid Land, 13(1): 98-106. https://doi.org/10.1007/s40333-020-0071-0

\footnotetext{
"Corresponding author: WANG Yongdong (E-mail: wangyd@ms.xjb.ac.cn); LEI Jiaqiang (E-mail: leijq@ms.xjb.ac.cn) Received 2019-06-27; revised 2020-05-28; accepted 2020-06-05

(C) Xinjiang Institute of Ecology and Geography, Chinese Academy of Sciences, Science Press and Springer-Verlag GmbH Germany, part of Springer Nature 2021
} 


\section{Introduction}

Desertification, the symbol of environmental degradation and economic poverty, is an urgent environmental problem in the world and has attracted worldwide attention (Malagnoux et al., 2007; Ofori and Showstack, 2010; Yu et al., 2017). Apart from threatening the environment, desertification has also been an obstacle to the global economic development (Tuoheti et al., 2013). As the United Nations Development Program (UNDP) reported, the increasing rate of global desertification is approximately $5.0 \times 10^{4}-7.0 \times 10^{4} \mathrm{~km}^{2} / \mathrm{a}$. The economic loss, which affects about two-thirds of global dryland regions in 54 countries, adds up to $42.31 \times 10^{9}$ USD annually. China is one of the most severely desertified countries in the world (Nash, 1999). Desertification is especially severe in Xinjiang Uygur Autonomous Region, a typical arid and semi-arid area in China (Tuoheti et al., 2013; Li et al., 2015); therefore, desertification control is an urgent task in this region. Forestation is proved to be a vital eco-engineering measure for combating desertification and is widely used in the fragile regions of the world (Cao, 2008; Li et al., 2018). However, situations become complicated when forestation project is conducted in mobile desert regions, such as the Taklimakan Desert in southern Xinjiang, China (Li et al., 2017).

The Taklimakan Desert, the second largest mobile desert in the world, is located in the hinterland of the Tarim Basin in southern Xinjiang of China; it is an extremely arid region with mean annual precipitation of less than $50 \mathrm{~mm}$ and mean annual pan evaporation of $3000 \mathrm{~mm}$, especially, there is no runoff from the land surface (Lei et al., 2008; Zhang et al., 2017; Wang et al., 2018; Dong et al., 2020). Wind-blown sand is a serious environmental problem in the Taklimakan Desert. In addition, the vegetation community structure is simple and most areas have no organisms, so the region has been called the "Dead Sea" due to its harsh environment (Chen, 1993; Lei et al., 2008; Wang et al., 2008; Li et al., 2015). With the discovery of plentiful oil and gas resources in the Taklimakan Desert, the Taklimakan Desert Highway, the longest desert highway across the mobile desert in the world, was initially constructed in 1993 and completed in 1995. The Taklimakan Desert Highway has a total length of $446 \mathrm{~km}$ and has an important strategic significance for oil and gas resources exploration and the development of the Tarim Basin. It also plays a vital role in the socio-economic development of southern Xinjiang (Zhou et al., 2006; Li et al., 2015).

A series of mechanical control measures (e.g., sand barrier fences) were built early in the life of the Taklimakan Desert Highway to prevent the desert highway from wind erosion. Unfortunately, more than $70 \%$ of the sand barrier fences and straw checkerboard barriers have lost their functions, and the desert highway has often been buried and frequently blocked since 1999 . Therefore, a long green corridor (artificial shelterbelt) with the length of $437 \mathrm{~km}$ was built along the Taklimakan Desert Highway to protect the highway (Xu et al., 2006; Huang et al., 2015; Zhang et al., 2016). However, some potential problems still exist for the sustainable development of the desert highway, such as water shortage, strong sandstorms, extreme environmental characteristics and large maintenance costs.

In this study, we thoroughly discussed the cause of wind-blown sand damage and its threaten to the Taklimakan Desert Highway. We also systematically described the sand control measures along the desert highway, such as the efficiency of the mechanical and biological sand control systems, and provided some suggestions for the biological sand control system to ensure the sustainable development of the desert highway.

\section{The causes of wind-blown sand damage}

Generally, the occurrence of wind-blown sand damage needs to meet three basic conditions: strong wind power, complex landforms and abundant sand sources (Lei et al., 2008). Unfortunately, all these conditions occur along the Taklimakan Desert Highway. Therefore, the desert highway is easily subjected to wind-blown sand damage. 


\subsection{Strong wind power}

The degree of wind-blown sand damage is related to the intensity of sand blowing activity; the stronger the wind power, the higher the degree of damage. Therefore, the intensity of wind power can reflect the degree of wind-blown sand damage (Han et al., 2003). Wind-blown sand is a serious problem in the Taklimakan Desert, as the region is characterized by an annual average wind speed of $2.0 \mathrm{~m} / \mathrm{s}$, a maximum instantaneous wind speed of $20.0 \mathrm{~m} / \mathrm{s}$ and the sand-shifting windy weather of more than $130 \mathrm{~d} / \mathrm{a}$. Wind power is primarily controlled by the airflow through the eastern gap in the Tarim Basin and the downdraft from the Tianshan Mountains (Dong et al., 2004; Zhang et al., 2017). Strong wind and steady wind direction provide the dynamic conditions for the occurrence of wind-blown sand along the Taklimakan Desert Highway (Han et al., 2003).

\subsection{Complex landforms}

The influence of topography or landform characteristics on sand movement occurs mainly in the redistribution of wind power, such as the direction, form and strength of airflow. Additionally, complex landforms are not only the exchange interface of energy and material for wind and sand but also the product of the interaction between wind and sand. Complex and diverse landforms, especially the shapes and scales of sand dunes, are greatly differentiated along both sides of the Taklimakan Desert Highway, which can greatly impact wind-blown sand (Zhu et al., 1981; Wang et al., 2000).

\subsection{Abundant sand sources}

The coverage of wind-blown sand is high along the Taklimakan Desert Highway and the sand is mostly composed of fine and very fine sand particles. Specifically, about $61.3 \%$ of the desert highway region is covered by mobile sand dunes on its both sides, with fine and very fine sand particles making up nearly $90.0 \%$ of the total sand content (Chen, 1993). Additionally, the incomplete development of soil conditions and low plant coverage along the Taklimakan Desert Highway also increase the abundance of sand amounts (Dong et al., 2004).

\section{Wind-blown sand damage to the desert highway}

Damage from wind-blown sand to the desert highway usually includes three aspects in terms of its dynamic process (Johnson, 1996; Khier et al., 2000; Han et al., 2007). The first aspect is aeolian erosion, which mostly occurs in the region with strong windy conditions, bare land surfaces and sparse vegetation coverage (Copley, 1987; Bergstrom et al., 1992; Zhang et al., 2010). Most sections along the desert highway are located in the center of the strong windy region, with the sand-shifting windy weather occurring more than $130 \mathrm{~d} / \mathrm{a}$. Therefore, strong wind will provide sufficient energy for sand activities along the Taklimakan Desert Highway (Wang et al., 2008). The second aspect is sand aggregation that buries the sand barrier fences and straw checkerboard barriers, ultimately resulting in sand deposition on the road surface and road shoulders. The third aspect is moving dune coverage, especially on the road surface and road shoulders.

\subsection{Aeolian erosion}

The damage of aeolian erosion mainly undercuts and moves the sand barrier fences along the Taklimakan Desert Highway. When the airflow is blocked by a fence, it forms a reflux at the interior of the fence bottom; in this case, the reflux induces the wind-blown sand materials, gradually undercutting and moving the fence fixed piles. Ultimately, the fence fixed piles lose their stability or are completely exposed. Additionally, combined with the pressure effect by blowing wind, the sand barrier fences are lodged and lacked resistance. In the sand-fixing band, aeolian erosion on the straw checkerboard barriers leads to a blowout pit at a certain range in the upper windward and leeward of the dune slope.

\subsection{Sand aggregation}

Sand aggregation is formed when the wind speed decreases after encountering obstacles, which 
can reduce the ability of wind to carry sand and lead to sand deposition on the road surface and road shoulders. For the sand control system of the desert highway, sand aggregation forms around the sand barrier fences and buries the fences when the sand flow encounters the periphery of the sand barrier fences. When the resistance ability of the sand barrier fences weakens, the sand flow in the leeward side forms sand-fallen slopes and moves forward as shifting sand. Thus, the sand flow, once formed within the sand control system, will produce stranded sand, bury the straw checkerboard barriers and form sheet-sand aggregation on the road surface and road shoulders, thereby endangering the smoothness of the desert highway.

\subsection{Moving dune coverage}

The moving dune coverage is also caused by sand aggregation, which is mainly manifested as the forward movement of sand dunes and the burying of sand aggregation to the sand control system or the desert highway. In addition to the risk of peripheral burying of the sand control system, the movement of sand dunes also results in the covering of the straw checkerboard barriers as well as the road surface and road shoulders.

\section{Sand control measures for the wind-blown sand damage}

\subsection{Mechanical sand control measure}

The mechanical sand control system is composed of two parts: sand-blocking (sand barrier fences, such as reeds and nylon mesh) and sand-fixing (straw checkerboard barriers) parts. Its specific structure from the exterior to the interior is as follows: sand barrier fences (e.g., reeds or nylon mesh), deposited sand belt and straw checkerboard barriers (Fig. 1) (Lei et al., 2003; Zhang et al., 2009). The height of the sand barrier fences is approximately $1.1 \mathrm{~m}$, and the fences are arranged in parallel at the outermost edge of the desert highway as the sand-blocking belt. The deposited sand belt is generally 10-20 m in width. It is deposited between the sand barrier fences as a sand-fixing belt. The grid size of the straw checkerboard (sand-fixing belt) is $1 \mathrm{~m} \times 1 \mathrm{~m}$, and the width is 50-70 $\mathrm{m}$ on the windward side and 40-60 $\mathrm{m}$ on the leeward side (Xu et al., 2006).

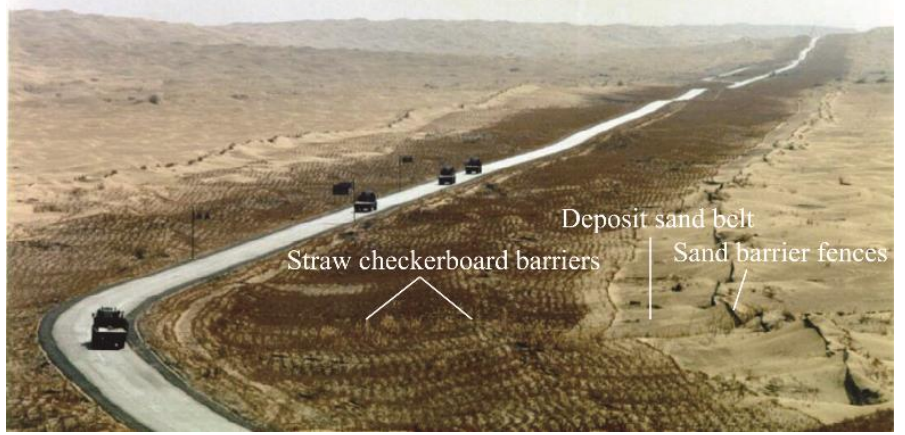

Fig. 1 Structure of the mechanical sand control system along the Taklimakan Desert Highway

For the Taklimakan Desert Highway, more than $70 \%$ of the sand barrier fences and straw checkerboard barriers have lost their functions since 1999. Most of the sand barrier fences were buried (Fig. 2a), and large amounts of sand aggregated in the straw checkerboard barriers (Fig. 2b). Finally, mostly shifting sand or sand dunes buried the desert highway (Fig. 2c) (Lei et al., 2003). From Table 1 we can find that, the degree of the three types of damage on the straw checkerboard barriers in typical sections along the Taklimakan Desert Highway presented an increasing trend from March 1997 to May 1999, with the total damaged area reaching $90.50 \%$ on the east side of the desert highway and $77.77 \%$ on the west side in May 1999 (Table 1). The degree of the three types of damage on the sand barrier fences in typical sections along the Taklimakan Desert Highway presented a similar trend with the straw checkerboard barriers from March 1997 to May 
1999, and the total damaged area reached $89.85 \%$ on the east side of the desert highway and $75.81 \%$ on the west side in May 1999 (Table 2).
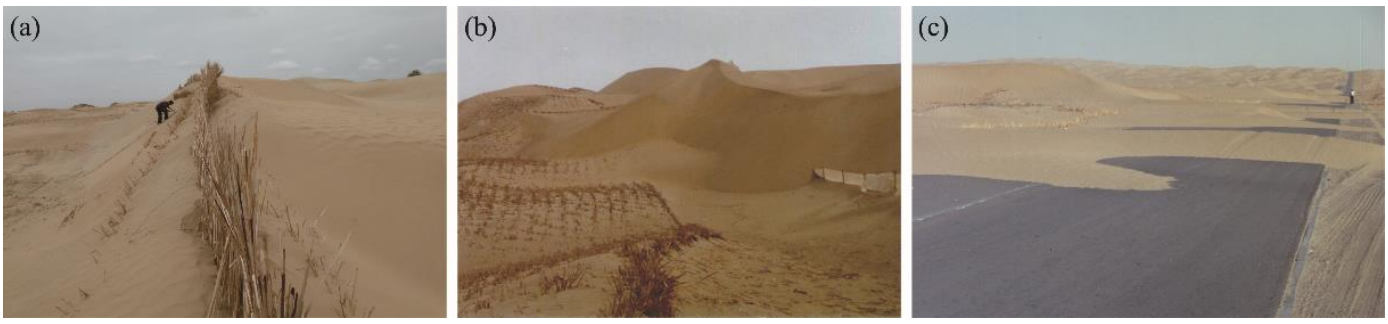

Fig. 2 Damage conditions of the mechanical sand control system caused by wind-blown sand along the Taklimakan Desert Highway. (a), buried sand barrier fences; (b), sand aggregation in the straw checkerboard barriers; (c), moving dune coverage on the desert highway.

Table 1 Damage conditions of the straw checkerboard barriers in typical sections along the Taklimakan Desert Highway

\begin{tabular}{|c|c|c|c|c|c|c|}
\hline \multirow{3}{*}{ Damage ways } & \multicolumn{6}{|c|}{ Percentage of damaged area $(\%)$} \\
\hline & \multicolumn{3}{|c|}{ East side of the highway } & \multicolumn{3}{|c|}{ West side of the highway } \\
\hline & Mar 1997 & Oct 1997 & May 1999 & Mar 1997 & Oct 1997 & May 1999 \\
\hline Aeolian erosion & 8.49 & 9.65 & 12.00 & 6.40 & 9.21 & 4.63 \\
\hline Sand aggregation & 24.85 & 38.14 & 53.36 & 27.81 & 23.96 & 55.73 \\
\hline Moving dune coverage & 4.38 & 28.52 & 25.14 & 1.48 & 8.86 & 17.41 \\
\hline Total & 37.72 & 76.31 & 90.50 & 35.69 & 42.03 & 77.77 \\
\hline
\end{tabular}

Table 2 Damage conditions of the sand barrier fences in typical sections along the Taklimakan Desert Highway

\begin{tabular}{|c|c|c|c|c|c|c|}
\hline \multirow{3}{*}{ Damage ways } & \multicolumn{6}{|c|}{ Percentage of damaged area $(\%)$} \\
\hline & \multicolumn{3}{|c|}{ East side of the highway } & \multicolumn{3}{|c|}{ West side of the highway } \\
\hline & Mar 1997 & Oct 1997 & May 1999 & Mar 1997 & Oct 1997 & May 1999 \\
\hline Aeolian erosion & 15.49 & 38.48 & 46.69 & 23.75 & 24.05 & 24.08 \\
\hline Sand aggregation & 21.23 & 22.82 & 10.45 & 9.74 & 12.45 & 36.64 \\
\hline Moving dune coverage & 22.38 & 25.13 & 32.71 & 1.63 & 12.36 & 15.09 \\
\hline Total & 59.10 & 86.43 & 89.85 & 35.12 & 48.86 & 75.81 \\
\hline
\end{tabular}

\subsection{Biological sand control measure}

In 2000, an eco-engineering artificial shelterbelt (including 40 species belonging to three genera: Haloxylon, Tamarix and Calligonum) with the length of $437 \mathrm{~km}$ and width of 70-100 m was built along the Taklimakan Desert Highway to prevent desertification. This biological sand control system is composed of sand-blocking and sand-fixing parts and includes three patterns of biological sand encroachment control measures, which are presented in Figure 3. At the interdune and sparsely distributed dune sections, the structure of the biological sand control measure along the wind direction is composed of two sand-fixing belts and two sand-blocking belts, totally four belts (Fig. 3a). At the transition sections between the ridges and depressions, there are three belts, i.e., sand-fixing belt-sand-fixing belt-sand-blocking belt (Fig. 3b), while at the high compound ridge sections, two belts (sand-fixing belt-sand-fixing belt) are distributed (Fig. 3c). It should be noted that plant species are irrigated using saline groundwater along the desert highway (Xu et al., 2006).

At present, the artificial shelterbelt appears to be stable, and its benefits on sand erosion control along the desert highway are manifested as many aspects (Fig. 4). First, the artificial shelterbelt can effectively reduce wind speed and control aeolian erosion. For instance, the wind speed at the height of $1.0 \mathrm{~m}$ above the mobile dunes is $6.6 \mathrm{~m} / \mathrm{s}$, while it decreases to $1.5-3.3 \mathrm{~m} / \mathrm{s}$ within the artificial shelterbelt; therefore, there is no sand generally blows on the road surface, except under 

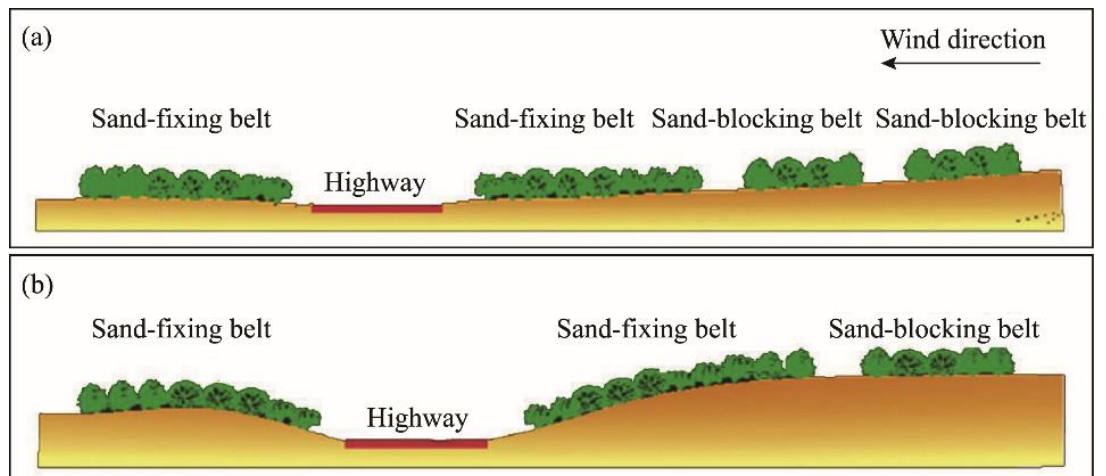

(c)

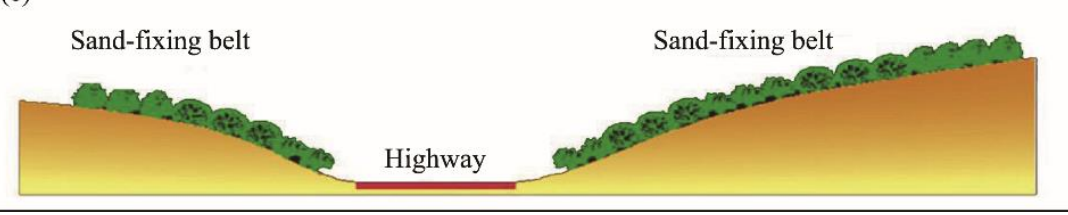

Fig. 3 Three patterns of the biological sand control measures along the Taklimakan Desert Highway. (a), four belts (two sand-fixing belts and two sand-blocking belts) at the interdune and sparsely distributed dune sections; (b), three belts (sand-fixing belt-sand-fixing belt-sand-blocking belt) at the transition sections between the ridges and depressions; (c), two belts (sand-fixing belt-sand-fixing belt) at the high compound ridge sections.

(a)

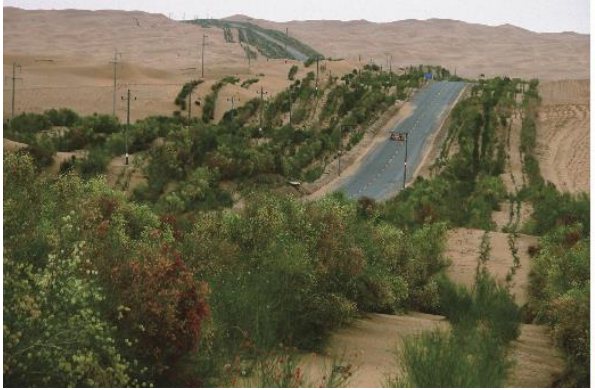

(b)

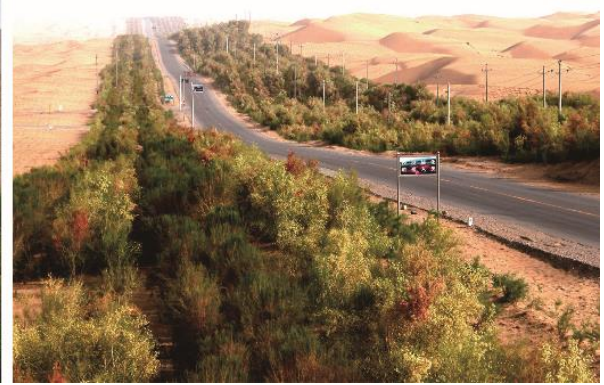

Fig. 4 Protection effects of the artificial shelterbelt along the Taklimakan Desert Highway

strong sandstorm conditions (Lei et al., 2008). Second, the artificial shelterbelt improves the soil properties effectively by increasing soil water and nutrient $(\mathrm{C}, \mathrm{N}$ and $\mathrm{P})$ contents and decreasing soil bulk density, which inevitably makes the aeolian soil gradually change to fixed and semi-fixed soil (Gu et al., 2000; Jin et al., 2008). Third, the artificial shelterbelt can improve the biodiversity, especially for herbs and animals; approximately 13 herb species have been found since the artificial shelterbelt was built, benefiting the vegetation recovery (Zhang et al., 2011). Fourth, the artificial shelterbelt ameliorates the local micro-climate; the air temperature decreases while the relative humidity increases due to the plant transpiration and the absorption and reflection of solar radiation by the shelterbelt canopy (Lei et al., 2008). Additionally, the artificial shelterbelt effectively enhances the $\mathrm{C}$ sequestration capacity through plant photosynthesis (Mariscal et al., 2007). In short, the artificial shelterbelt not only ensures the smoothness of the desert highway but also ameliorates the local ecological environment, playing a vital role in ecological restoration and environmental protection in the Taklimakan Desert.

\subsection{Effects of different sand control measures along the Taklimakan Desert Highway}

Researchers have conducted various experiments of mechanical, biological and chemical sand control measures along the Taklimakan Desert Highway to determine their control effects (Table 
3). The experiments showed that the chemical sand control measure is ineffective and thus is not applied to the whole protection system along the Taklimakan Desert Highway. As for the control effects with respect to the ecological benefits and sustainability, the biological sand control measure is better than the mechanical and chemical sand control measures; however, its investment is higher (Table 3). Specifically, the investment of the biological sand control measure is 2-3 times greater than those of the other two sand control measures during a relatively short term ( $<15$ a) (Gong et al., 2001). However, concerning the sustainability and eco-efficiency or the development of the desert industry, the biological sand control measure most likely reduces its investment over the long term scale. Therefore, it is the most effective protection measure for the sustainable development of the desert highway.

Table 3 Effects and investment of different sand control measures

\begin{tabular}{|c|c|c|c|c|}
\hline $\begin{array}{c}\text { Sand control } \\
\text { measure }\end{array}$ & Effects & $\begin{array}{c}\text { Investment } \\
(\mathrm{CNY} /(\mathrm{km} \cdot \mathrm{a}))\end{array}$ & Ecological benefit & Sustainability \\
\hline $\begin{array}{l}\text { Mechanical } \\
\text { sand control } \\
\text { measure }\end{array}$ & $\begin{array}{l}\text { More than } 70 \% \text { of the control } \\
\text { measure is ineffective: the sand } \\
\text { barrier fences are buried, and straw } \\
\text { checkerboard barriers containing } \\
\text { aggregated sand and moving dunes } \\
\text { bury the desert highway (Lei et al., } \\
2008 \text { ) }\end{array}$ & $\begin{array}{l}0.50 \times 10^{6}-0.77 \times 10^{6} \\
(\text { Gong et al., } 2001)\end{array}$ & No & Unsustainable \\
\hline $\begin{array}{l}\text { Biological } \\
\text { sand control } \\
\text { measure }\end{array}$ & $\begin{array}{l}\text { More than } 90 \% \text { of the artificial } \\
\text { shelterbelt is effective; there is } \\
\text { generally no sand on the road } \\
\text { surface, except under strong } \\
\text { sandstorm conditions (Lei et al., } \\
\text { 2008) }\end{array}$ & $\begin{array}{l}1.30 \times 10^{6}-1.70 \times 10^{6} \\
\text { (Gong et al., } 2001 \text { ) }\end{array}$ & $\begin{array}{l}\text { Increasing the biodiversity } \\
\text { and improving the } \\
\text { eco-environment (Lei et al., } \\
\text { 2008; Zhang et al., 2011) }\end{array}$ & Sustainable \\
\hline $\begin{array}{l}\text { Chemical } \\
\text { sand control } \\
\text { measure }\end{array}$ & Ineffective (Xu et al., 1998) & $\begin{array}{l}0.40 \times 10^{6}-1.20 \times 10^{6} \\
\text { (Gong et al., } 2001 \text { ) }\end{array}$ & $\begin{array}{l}\text { Bring chemical materials to } \\
\text { the desert and damaging the } \\
\text { eco-environment (Xu et al., } \\
\text { 1998; Han et al., 2000) }\end{array}$ & Unsustainable \\
\hline
\end{tabular}

Although the artificial shelterbelt greatly benefits the smoothness and ecological restoration of the Taklimakan Desert Highway, issues for its sustainable development still remain. For example, we acknowledge that scientific artificial shelterbelt planting may be significant for habitat improvement and vegetation rehabilitation, but it remains unclear whether species screening and irrigation technology are rational. Additionally, whether long-term saline irrigation will have a great impact on the quality of plants and the reserves and quality of groundwater is still unknown. Furthermore, without financial support, the high maintenance cost of the artificial shelterbelt undoubtedly hinders the sustainable development of the desert highway and the shelterbelt itself. All these questions need further in-depth study in the future.

Some suggestions are presented here to address these problems. First, although current studies have shown that long-term saline irrigation did not impact the quality of groundwater, its future status or influence is still unknown (Zhang et al., 2016). Hence, we should increase the long-term groundwater monitoring to understand the dynamics and hydrological characteristics of groundwater and, ultimately, to predict its future development (Fan et al., 2017; Wei et al., 2017). In addition, we can screen drought-resistant species to reduce the irrigation requirement and ensure the sound development of groundwater ( $\mathrm{Li}$ et al., 2015). Second, long-term irrigation with saline water will inevitably cause soil salinity accumulation; therefore, halophyte screening is essential for vegetation restoration (Zhang et al., 2016). Third, due to the high cost of maintenance on the desert highway and artificial shelterbelt (approximately $3.0 \times 10^{7} \mathrm{CNY} / \mathrm{a}$ ), it is necessary to improve the economic efficiency. For example, planting cash crops, such as species of Cistanche, Lycium and Apocynum, can be considered. It has been reported that vaccinating Cistanche with a suitable density along the artificial shelterbelt of the Taklimakan Desert Highway will generate a high income of $9.0 \times 10^{6} \mathrm{CNY} / \mathrm{a}$, and that developing a biological salt industry not only can increase the economic income but also can remove the salts from the soil (Xu et al., 2006). 


\section{Conclusions}

This study showed that the wind-blown sand damage of aeolian erosion, sand aggregation and moving dune coverage exert great damage or threaten to the Taklimakan Desert Highway. Comparisons of the effects of different sand control measures along the Taklimakan Desert Highway showed that the biological sand control system is the most effective protection measure for the sustainable development of the desert highway. However, there are still some problems influence the sustainable development of the biological sand control system and the desert high way. Therefore, we provide some suggestions to address these problems. First, screening drought-resistant species is recommended because it can reduce the irrigation requirement and ensure the sound development of groundwater and the sustainable development of the highway. Second, screening halophytes is also essential for vegetation restoration. Third, planting cash crops, such as Cistanche, Wolfberry and Apocynum is a good approach to decrease the high cost of maintenance on the desert highway and shelterbelts. In conclusion, desertification control and the protection (restoration) and utilization of plants in desert regions should focus on social and economic benefits as well as eco-efficiency. Only then we can ensure that this process is sustainable development.

\section{Acknowledgements}

This work was supported by the National Natural Science Foundation of China $(31971731$, 41771121), the Xinjiang National Key Research and Development Program (2019B00005), the National Key Research and Development Program (2017YFC0506705), and the Youth Innovation Promotion Association of Chinese Academy of Sciences (2017476).

\section{References}

Bergstrom D J, Boucher K M, Derksen D. 1992. Wind flow over an elevated roadway. Journal of Wind Engineering and Industrial Aerodynamics, 41-44: 2697-2698.

Cao S X. 2008. Why large-scale afforestation efforts in China have failed to solve the desertification problem. Environmental Science Technololy, 42(6): 1826-1831.

Chen W N. 1993. Grain size parameters of aeolion sediments in the vicinity of the longitude $84^{\circ} \mathrm{E}$, Taklimakan Desert. Acta Geographica Sinica, 48(1): 33-46. (in Chinese)

Copley J M. 1987. The three dimensional flow around railway trains. Journal of Wind Engineering and Industrial Aerodynamics, 26(1): 21-52.

Dong Z B, Chen G T, He X D, et al. 2004. Controlling blown sand along the highway crossing the Taklimakan Desert. Journal of Arid Environments, 57(3): 329-344.

Dong Z W, Li C J, Li S Y, et al. 2020. Stoichiometric features of C, N, and P in soil and litter of Tamarix cones and their relationship with environmental factors in the Taklimakan Desert, China. Journal of Soils and Sediments, 20(2): 690-704.

Fan J L, Wei Y P, Xu X W, et al. 2017. Effect of drip irrigation with saline water on the construction of shelterbelts for soil and groundwater protection in the hinterland of the Taklimakan Desert, China. Tecnologia Y Ciencias Del Agua, 8(2): 19-30.

Gong F H, He X D, Peng X Y, et al. 2001. Comparison of properties and cost of different sand-fixing system along Tarim Desert Highway. Journal of Desert Research, 21(1): 45-49. (in Chinese)

Gu F X, Wen Q K, Pan B R. 2000. Research on soil physico-chemical properties of artificial vegetation in center of Taklimakan Desert. Journal of Arid Land Resources and Environment, 14(1): 74-79. (in Chinese)

Han Z, Wang T, Dong Z, et al. 2007. Chemical stabilization of mobile dunefields along a highway in the Taklimakan Desert of China. Journal of Arid Environments, 68(2): 260-270.

Han Z W, Yao Z Y, Shao G S. 2000. Approaches to several problems concerning sand control system of Tarim Desert highway. Arid Land Resources and Environment, 2: 35-40. (in Chinese)

Han Z W, Wang T, Sun Q W, et al. 2003. Sand harm in Taklimakan Desert Highway and sand control. Acta Geographic Sinica, 13(1): 45-52. (in Chinese)

Huang Y, Wang Y D, Zhao Y. 2015. Spatiotemporal distribution of soil moisture and salinity in the Taklimakan Desert Highway Shelterbelt. Water, 7(8): 4343-4361.

Jin Z Z, Lei J Q, Xu X W, et al. 2008. Evaluation of soil fertility of the shelter-forest land along the Trim Desert Highway. Chinese Science Bulletin, 53(Supp II): 125-136. 
Johnson T. 1996. Strong wind effects on railway operations $-16^{\text {th }}$ October 1987. Journal of Wind Engineering and Industrial Aerodynamics, 60: 251-266.

Khier W, Breuer M, Durst F. 2000. Flow structure around trains under side wind conditions: A numerical study. Computers \& Fluids, 29(2): 179-195.

Lei J Q, Wang X Q, Wang D. 2003. The formation of the blown sand disaster to the Tarim Desert Highway, Xinjiang, China. Arid Zone Research, 20(1): 1-6. (in Chinese)

Lei J Q, Li S Y, Jin Z Z. 2008. Comprehensive eco-environmental effects of the shelter-forest ecological engineering along the Tarim Desert Highway. Chinese Science Bulletin, 53(Supp II): 190-202.

Li B W, Xu X W, Lei J Q. 2008. Site type classification for the shelter-forest ecological project along the Tarim Desert Highway. Chinese Science Bulletin, 53(Supp II): 31-40.

Li C J, Li Y, Ma J. 2011. Spatial heterogeneity of soil chemical properties at fine scales induced by Haloxylon ammodendron (Chenopodiaceae) plants in a sandy desert. Ecological Research, 26(2): 385-394.

Li C J, Lei J Q, Zhao Y. 2015. Effect of saline water irrigation on soil development and plant growth in the Taklimakan Desert Highway shelterbelt. Soil Tillage Research, 146: 99-107.

Li C J, Shi X, Mohamad O A. 2017. Moderate irrigation intervals facilitate establishment of two desert shrubs in the Taklimakan Desert Highway Shelterbelt in China. PLoS ONE, 12(7): e0180875, doi: 10.1371/journal.pone.0180875.

Li C J, Liu R, Wang S J. 2018. Growth and sustainability of Suaeda salsa in the Lop Nur, China. Journal of Arid Land, 10(3): 429-440.

Li S Y, Tang Q L, Lei J Q. 2015. An overview of non-conventional water resource utilization technologies for biological sand control in Xinjiang, northwest China. Environmental Earth Sciences, 73(2): 7873-7885.

Malagnoux M, Sène E H, Atzmon N. 2007. Forests, trees and water in arid lands: A delicate balance. Unasylva, 58(229): $24-29$.

Mariscal I, Pereqrina F, Terefe T. 2007. Evolution of some physical properties related to soil quality in the degraded ecosystems of "raña" formations from SW Spain. Science of The Total Environment, 378(1-2): 130-132.

Nash D J. 1999. World atlas of desertification. Geographical Journal, 165: 325-326.

Ofori L, Showstack R. 2010. Desertification awareness decade. EOS Transactions American Geophysical Union, 91(37): 327.

Tuoheti N, Abulaiti M, Ahmed Z. 2013. Anti-desertification legislation and ecological problems in Xinjiang China. Journal of Politics and Law, 6(3): 160-168.

Wang H F, Lei J Q, Li S Y, et al. 2008. Effect of the shelterbelt along the Tarim Desert Highway on air temperature and humidity. Chinese Science Bulletin, 53: 41-52.

Wang X Q, Lei J Q, Huang Q. 2000. Study on spatial distribution of wind-sand hazard along Tarim Desert Highway. Journal of Desert Research, 20(4): 438-442. (in Chinese)

Wang Y D, Zhao Y, Li S Y. 2018. Soil aggregation formation in relation to planting time, water salinity, and species in the Taklimakan Desert Highway shelterbelt. Journal of Soils and Sediments, 18(4): 1466-1477.

Wei Y P, Fan J L, Xu X W, et al. 2017. Water table response to a pumping test in the hinterland core area of the Taklimakan Desert, China. Tecnologia Y Ciencias Del Agua, 8(2): 151-158.

Xu X W, Hu Y K, Pan B R. 1998. Analysis on protection effect of various measures of combating drifting sand on Tarim Desert Highway. Arid Zone Research, 15(1): 21-26. (in Chinese)

Xu X W, Li B W, Wang X J. 2006. Progress in study on irrigation practice with saline groundwater on sandlands of Taklimakan Desert Hinterland. Chinese Science Bulletin, 51(Supp I): 161-166.

Yu X X, Li S Y, Wang H F. 2017. Aeolian-sand flow structure at different locations along desert highway shelterbelt. Arid Zone Research, 34(3): 21-26. (in Chinese)

Zhang J, Li S Y, Jin Z Z. 2011. Relationship between species diversity of herbaceous plants in the shelterbelt and environment factors. Arid Zone Research, 28(1): 118-125. (in Chinese)

Zhang J G, Xu X W, Lei J Q. 2009. Progress in the researches of sand drift disasters and defense system along the Tarim Desert Highway. Journal of Northwest Forestry University, 24(2): 50-54. (in Chinese)

Zhang J G, Lei J Q, Wang Y D. 2016. Survival and growth of three afforestation species under high saline drip irrigation in the Taklimakan Desert, China. Ecosphere, 7(5): e01285, doi: 10.1002/ecs2.1285.

Zhang K C, Qu J J, Liao K T. 2010. Damage by wind-blown sand and its control along Qinghai-Tibet Railway in China. Aeolian Research, 1(3-4): 143-146.

Zhang X M, Wang Y D, Zhao Y, et al. 2017. Litter decomposition and nutrient dynamics of three woody halophytes in the Taklimakan Desert Highway Shelterbelt. Arid Land Research and Management, 31(3): 335-351.

Zhou Z B, Xu X W, Lei J Q. 2006. Salt balance and movement of Tarim Desert Highway Shelterbelt irrigated by saline water. Arid Land Geography, 29(4): 470-475. (in Chinese)

Zhu Z D, Chen Z, Wu Z, et al. 1981. Study on the Geomorphology of Wind-Droft Sands in the Taklimakan Desert. Beijing: Science Press, 27-70. (in Chinese) 